punto org

General Editor Luigi Maria Sicca

43 
Rebecca Pera

\title{
WHEN CONSUMERS GET CREATIVE
}

Cocreation in the individual and collective realm

\author{
preface \\ Daniele Dalli
}

Editoriale Scientifica

Napoli 
All rights reserved

(C) Copyright 2018 by Editoriale Scientifica s.r.1.

Via San Biagio dei Librai, 39 - 80138 Napoli

www.editorialescientifica.com info@editorialescientifica.com

ISBN 978-88-9391-348-5 


\section{Table of Contents}

9 Preface

Daniele Dalli

13 Acknowledgements

17 Introduction

21 1. Do what it takes. Shifting the paradigm from PRODUCER TO CONSUMER INNOVATION

22 1.1. The traditional perspective

24 1.2. The new cocreative paradigm

31 1.3. Defining the concept of cocreation

31 1.4. Anatomy of cocreation

35 1.5. Value Cocreation Models

35 1.5.1. The DART model

40 1.5.2. Payne's model: The process

42 1.5.3. Gronroos's model: The actor's perspective

45 1.6. Consumer cocreation in New Product Development

46 1.6.1. Consumer motivators: Why consumers cocreate?

50 1.6.2. Impediments and Stimulators of Consumer Cocreation

51 1.6.3. Outcomes of Consumer Cocreation: What are the implications for companies?

52 1.7. Case Study. Muji: the dawn of crowdsourcing and user generated products

60 1.8. Case study. Spotify: playlists and data driven campaigns 
173 Conclusion: You buy what is yours: is it all a goody-goody new paradigm?

179 References

189 Figure index

191 punto org book series

2. Bypassing the obstacle. Constraints are stimuli WHEN CONSUMERS BECOME PROBLEM SOLVERS 2.1. Individual Motives 2.3. Individual Opportunities 2.4. Individual Models of the creative process 2.5. A taxonomy of Creative Outcomes 2.6. Engineering Magic by Roberto Fassone 2.7. Non-Intentional Design and spontaneous creativity

3. Beyond myself: creativity in Online Creative Consumer Communities

3.1. Collective Motives: Purpose and constraints

3.2. Collective Abilities: Distributed knowledge and skills

3.3. Collective Opportunity: Collaboration and Leaderships

3.4. The idea generation process in collective creative communities Mazzarino

3.6. Case study. The Maker Community

4. If YOU CAN'T BEAT THEM, JOIN THEM! MANAgerial APPROACHES TOWARDS CONSUMER CREATIVITY

4.1. Discouragement or engagement?

4.2. Mentos and Coca- cola geysers - a Vital explosion

4.3. Lesson learnt: four postures to consumers' creativity

4.4. Managerial implications: What is your posture? 


\title{
Preface
}

\author{
Daniele Dalli*
}

This study deals with the theme of creativity and the contribution that consumers make to it. For a long time, the subject has been a matter of debate in different disciplinary areas; contributions arrive from management, design and technology, others from economics and sociology. Only recently, such different perspectives have been framed under a unifying paradigm, the cocreation one. Broadly speaking, cocreation refers to the phenomenon according to which the traditional economic fences, those that separate suppliers and clients, producers and consumers, economic exchange and social exchange, are losing relevance. This occurs because of an "emerging creativity" which generates value for goods and services through the collaboration and interaction among several different subjects, belonging to very different institutional contexts. Innovation is no longer led by companies and organized within their organizational hierarchies. It takes place, instead, in hybrid contexts (economic and social) where end consumers play increasingly a leading role. As such, the term consumer cannot be interpreted in a neo-classical sense, as the subject who consumes, uses and ultimately appropriates the utility embedded in products and services. Rather, it must be read in a wider sense, recognizing that consumers play an active

* Full Professor of Marketing and Consumer Behavior - Department of Economics and Management - University of Pisa. 
role in creating value. Consumers create value around goods and services offered by companies in countless ways: they contribute to the definition of technical specifications, to the definition of price, to the design of communication, to the enactment of pre and post-sales services, and so on. Conversely, in some cases, they contribute to reducing the value of assets. This occurs when the relationship with the companies providing the products or services does not correspond to criteria of fairness, mutual recognition, and collaboration.

The convergence of studies on creativity towards the cocreation strand is theoretically explained, with scholars by various backgrounds who, on the basis of the contributions of Prahalad and Ramaswamy (2000, 2004), have first placed consumer creativity and innovation on the same level of the corporate ones. Such research stream highlights the importance and the necessity of the integration of consumer creativity and innovation, which, with a series of technological and institutional changes has seen individuals undertake personal and professional innovative trajectories of value generation in a broad sense. Perhaps, the first example is the Innocentive platform, an independent business since 2001, which was founded by Lilly with the aim to organize the work of a multitude of freelance researchers who contributed to the innovation processes in the pharmaceutical field. Since this first platform many others in various fields were generated, from technology to the arts, from production to communication. They all have in common the facilitation of bridging creative consumers with business. In these platforms a synthesis is made between individual initiatives (personal and professional growth paths) and collective phenomena (innocrowding, crowd sourcing, and so on) with the formation of real communities that act as partners and sometimes as business counterparts.

Considering the creativity of consumers as one of the most important engines for cocreation means rewriting or modifying certain economic and managerial theory assumptions. It also 
determines important implications regarding the actions of companies and institutions. First, it involves revisiting the concept of the market which cannot be seen as an area of confrontation between supply and demand, rather a hybrid institution in which economic and social exchanges coexist. The contributions of sociology and anthropology to the study of markets have been essential to understand the ways in which consumers contribute to the cocreation of the value provided by suppliers. The theories on competition have therefore opened not only to the simultaneous presence of competition and cooperation between companies and institutional partners (companies, public and non-profit organizations), but also to the inclusion of customers - and in particular end consumers - not only as stakeholders, but as real partners to be engaged and actively included in the processes of innovation and creation of value. A growing openness towards the "outside" of the company, which goes beyond merely economic and commercial logics is therefore occurring.

Consequently, by changing sich basic theoretical elements, the implications for practitioners will necessarily be relevant and must adapt to such change. In this direction, this essay helps to review and redefine some important aspects of the companies' organizational roles and functions involved in the management of the exchange processes (marketing, commercial) and innovation ( $R \& D$, production). Practitioners within these roles and functions will be increasingly focused in the engagement of consumers and their involvement in the cocreation processes and less in the management of the internal value chain, with substantial effects on cost structure and metrics to be used to evaluate labor productivity. As a corollary, dealing with consumers implies a background (education and experience) that cannot be limited to the technical dimension, be it managerial, engineering or scientific, but can range from social sciences, to humanistic and legal subjects. These skills are necessary to 
ensure an effective integration of consumers in the processes of cocreation. Conversely, the risk is that these actors, become antagonists and "destroyers" of value, instead of partners, and generators of value.

Another substantial aspect illustrated in the present volume is the distinction between the individual and collective dimensions of creativity: the author emphasizes with efficacy and clarity that these two dimensions are both essential to the success of cocreative innovation projects. The rules of psychology regarding the consumer/cocreator must be respected and, at the same time, marketing managers need to contribute by facilitating the organizing of groups and communities in a harmonious and effective manner with respect to the related business processes.

Finally, in the conclusions the author appropriately pays attention to a critical dimension of cocreation processes. In the relationship between business and the crowd there is an irreducible conflict area due to the interests of the parties involved that - under certain conditions - can be unaligned or even incompatible. The literature provides numerous cases in which large national and international groups, armed with the best intentions, have tried to engage end consumers to discover then that this openness can generate spaces of conflict, even very harsh. Taking a critical perspective requires to consider cocreation as an opportunity that needs to be evaluated with great caution and balance, where the collaboration with consumers cannot be taken for granted and - above all - that their willingness to be engaged is not "unconditional", rather it depends on the satisfaction of needs, expectations and conditions of reciprocity.

February 2018 


\section{Acknowledgements}

I would like to express my sincere gratitude to Prof. Giovanni Fraquelli for having created a fertile environment for my scientific development. Constant autonomy, openness, and freedom have nourished my passion for research.

I also thank my fellow colleague Giampaolo Viglia for the stimulating discussions, for the sleepless nights we have spent working before deadlines, and for all the fun we have had in the last five years. Again, I would never be able to carry out research without laughing about it.

Finally, I thank the two anonymous referees and the Editor Luigi Maria Sicca for their useful directions. 